\title{
Optimization of Controlled Water and Nitrogen Fertigation on Greenhouse Culture of Capsicum annuum
}

\author{
Youzhen Xiang, ${ }^{1,2}$ Haiyang Zou, ${ }^{1}$ Fucang Zhang ${ }^{\mathbb{D},}{ }^{1,2}$ You Wu, ${ }^{1}$ Shicheng Yan, \\ Xinyan Zhang, ${ }^{1}$ Jianke Tian, ${ }^{1}$ Shengcai Qiang, ${ }^{1}$ Haidong Wang, ${ }^{1}$ and Hanmi Zhou ${ }^{3}$ \\ ${ }^{1}$ College of Water Resources and Architectural Engineering, Northwest A\&F University, Yangling 712100, China \\ ${ }^{2}$ Key Laboratory of Agricultural Soil and Water Engineering in Arid and Semiarid Areas of Ministry of Education, \\ Northwest A\&F University, Yangling 712100, China \\ ${ }^{3}$ College of Agricultural Engineering, Henan University of Science and Technology, Luoyang 471003, China
}

Correspondence should be addressed to Fucang Zhang; zhangfc@nwsuaf.edu.cn

Received 6 November 2017; Accepted 18 February 2018; Published 15 April 2018

Academic Editor: Zhenli He

Copyright (C) 2018 Youzhen Xiang et al. This is an open access article distributed under the Creative Commons Attribution License, which permits unrestricted use, distribution, and reproduction in any medium, provided the original work is properly cited.

\begin{abstract}
This study investigated the effects of different combinations of irrigation and nitrogen levels on the growth of greenhouse sweet peppers, assessing yield, quality, water use efficiency (WUE), and partial factor productivity from applied N (PFPN). By using controlled drip irrigation, the optimal conditions for efficient, large-scale, high-yield, and high quality production of sweet peppers in Northwest China were determined. Using the local conventional irrigation and nitrogen regime as a control $\left(105 \% \mathrm{ET}_{0}, \mathrm{~N}\right.$ : $300 \mathrm{~kg} \cdot \mathrm{hm}^{-2}$ ), three alternative irrigation levels were also tested, at $90 \%, 75 \%$, and $60 \% \mathrm{ET}_{0}$. These were combined with nitrogen levels at $100 \%$, as the control, and $75 \%, 50 \%$, and $25 \%$, resulting in 16 combination treatments. The results show that different supplies of water and nitrogen nutrition had a significant impact on the growth, yield, WUE, PFPN, and quality of fruit. The treatments of $\mathrm{W}_{0.90} \mathrm{~N}_{0.75}, \mathrm{~W}_{0.90} \mathrm{~N}_{0.50}, \mathrm{~W}_{0.75} \mathrm{~N}_{0.75}$, and $\mathrm{W}_{0.75} \mathrm{~N}_{0.50}$ can better maintain the "source-sink" relationship of peppers. They increased the economic yield, WUE, and PFPN. A principal component analysis was performed to evaluate indicators of fruit quality, revealing that the treatment of $\mathrm{W}_{0.75} \mathrm{~N}_{0.50}$ resulted in the best fruit quality. For greenhouse sweet peppers produced in Northwest China, the combination of $\mathrm{W}_{0.90} \mathrm{~N}_{0.75}$ resulted in the highest economic yield of $34.85 \mathrm{~kg} \cdot \mathrm{hm}^{-2}$. The combination of $\mathrm{W}_{0.75} \mathrm{~N}_{0.75}$ had the highest WUE of $16.50 \mathrm{~kg} \cdot \mathrm{m}^{-3}$. The $\mathrm{W}_{0.75} \mathrm{~N}_{0.50}$ combination treatment had the highest fruit quality score. For sustainable ecological development and in view of limited water resources in the area, we recommend the $\mathrm{W}_{0.75} \mathrm{~N}_{0.50}$ combination treatment, since it could obtain the optimal fruit quality, while its economic yield and WUE were $9 \%$ and $4 \%$ less than the maximum, respectively. This study provides a theoretical basis for the optimal management of water and nitrogen during production of greenhouse sweet peppers in Northwest China.
\end{abstract}

\section{Introduction}

The ever-increasing imbalance between supply and demand of agricultural water has forced adjustments of modern agricultural irrigation practices [1]. Crop yields generally benefit from short growth cycles and the selection of highyield varieties that undergo rapid development, strategies that have effectively increased the income of farmers. However, in order to maximize yield, excessive irrigation and fertilization are often required, resulting in overuse and serious runoff of fertilizer. Other negative effects are more frequent plant diseases and pests [2], a reduction of product quality, less efficient water and fertilizer utilization [3], and damage to local soil and water environments [4].

Water and nitrogen are critical factors determining crop yield and quality [5]. Appropriate irrigation technologies and nitrogen application strategies can lead to high yields and growth efficiencies of crops. Compared to conventional furrow irrigation, fertigation (the injection of fertilizer solution into the soil) effectively reduces surface runoff, evaporation between plants, and deep percolation [6]. At the same time, the drip irrigation technology with small flow can lower the downward migration rate of nitrogen into the soil and reduce nutrient loss [7]. As a result, a suitable nutrient 
microenvironment in the crop root zone can be achieved, promoting absorption of nutrients into the crops.

C. annuum (L. var. grossum), a member of the Solanaceae, produces fruits with a high nutritional value. Its effective culture is strongly dependent on the environment [8], as the plant requires a constant supply of water and nutrients [9]. The availability of nitrogen is an important determinant of crop yield and quality, by directly affecting photosynthesis and the accumulation, transfer, and distribution of biomass [10]. Previously, the studies of water-fertilizer management mainly focused on irrigation methods [11], irrigation amount and frequency [12], and various types of fertilizers [13-15].

Lately, an improved fertigation technique was developed that applies nutrients with water to the crops. Compared to classical fertigation, this new technique significantly increases yield, water use efficiency (WUE), and nutrient use efficiency [16-22]. For instance, compared to conventional furrow irrigation, properly controlled fertigation increases the yield of $C$. annuum and enhances WUE [11,23]. It was experimentally shown that carefully determined fertilizer quantities could ensure high yield of $C$. annuum, at the same time reducing production costs [13]. Another study reported that compared to conventional furrow irrigation, an optimized fertigation strategy could increase the WUE of $C$. annuum by $95 \%$, saving water by $34 \%$ and fertilizer by $20 \%$ [15].

Few studies have investigated the comprehensive influence of a water-nitrogen coupling effect on the growth, yield, and quality of C. annuum, and a quantitative index remains to be determined. Particularly, fruit quality as a function of the water-nitrogen ratio has rarely been reported. Therefore, the experiments presented here aimed at enhancing the utilization of water and nitrogen as well as promoting yield and quality of C. annuum crops. Using an automatically controlled irrigation and fertilization system, plot tests were performed in a sunlight greenhouse to optimize water and nitrogen management and make full use of water-nitrogen synergistic effects. This work provides technical support for application of automatic water and nitrogen management systems in C. annuum cultivation under protected conditions and offers a scientific basis for reference of high quality, high efficiency, and large-scale production.

\section{Materials and Methods}

\subsection{Experimental Materials}

2.1.1. Experimental Plots. The experiments were conducted in a test area with the Guanzhong plain, China, located at $108^{\circ} 04^{\prime} \mathrm{E}$ and $34^{\circ} 20^{\prime} \mathrm{N}$. The work was performed between April and July 2014, in a sunlight greenhouse belonging to the Key Laboratory of the Ministry of Education for Agricultural Water and Soil Engineering in Arid Area, Northwest Agriculture and Forestry University, China. The greenhouse windows face south and north, with vents at the top and southern-facing bottom of the greenhouse. The test facility has an altitude of $521 \mathrm{~m}$ and warm temperature due to a local semihumid climate. The annual average temperature is $13^{\circ} \mathrm{C}$ with annual average precipitation from 550 to $600 \mathrm{~mm}$. The greenhouse measures $76 \mathrm{~m}$ in length, $7.5 \mathrm{~m}$ in width, and $2.8 \mathrm{~m}$ in height. Heavy soil (1\% sand, $72 \%$ silt, and $27 \%$ clay) was used, with details on its physical and chemical properties shown in Table 1 . The soil bulk density was measured by dry weight. Soil samples were collected from a depth between 0 and $80 \mathrm{~cm}$ (every $20 \mathrm{~cm}$ ) with a ring knife (diameter: $5 \mathrm{~cm}$, height: $5 \mathrm{~cm}$ ). A small weather station (HOBO Event Logger, Onset Computer Corporation, USA) was set up inside the greenhouse. The atmospheric pressure, temperature, photo synthetically active radiation (PAR), relative humidity, and meteorological factors such as solar radiation were recorded every 10 minutes. The obtained measurements confirmed that these parameters were comparable for all plots.

2.1.2. Fertigation Equipment. An online irrigation fertilizer applicator (NETAJET 3G INLINE, NETAFIM, Israel) was employed for fertigation, which can precisely apply and control fertilization based on the amount of irrigation water. The flow rate supported by this system is from 0.5 to $20 \mathrm{~m}^{3} \cdot \mathrm{h}^{-1}$. Venturi-type applicators were used, equipped with an optical fertilizer meter with a flow rate capacity from 30 to $300 \mathrm{~L} \cdot \mathrm{h}^{-1}$. Both fertilizer and acid solutions can be used. In addition, the system includes electrical conductivity (EC) and $\mathrm{pH}$ measurement and control modules. Drip irrigation pipe (inner diameter: $8 \mathrm{~mm}$ ) was employed using drip laterals with inline emitter, distanced at $30 \mathrm{~cm}$ between emitter, providing a flow rate of $2 \mathrm{~L} \cdot \mathrm{h}^{-1}$ for each emitter and pipe working pressure of $0.3 \mathrm{MPa}$.

2.1.3. C. annuum Type and Fertilizer Used. American C. annuum "Marco" (Capsicum annuum L. var. grossum Marcomi F1) was used, as this type is particularly suitable for greenhouse production. The long, lantern shaped fruit is green when young and turns red when ripe. The fertilizer used in the experiment contains urea, calcium superphosphate $\left(\mathrm{Ca}\left(\mathrm{H}_{2} \mathrm{PO}_{4}\right)_{2} \cdot 2 \mathrm{H}_{2} \mathrm{O}\right)$, and potassium chloride $(\mathrm{KCl})$.

2.2. Experimental Design. Two experimental variables were studied: the amount of irrigation water and the amount of nitrogen fertilizer. Based on the reference crop evapotranspiration $\left(\mathrm{ET}_{0}\right)$, four irrigation levels were tested, at $105 \% \mathrm{ET}_{0}$ $\left(\mathrm{W}_{1.05}\right), 90 \% \mathrm{ET}_{0}\left(\mathrm{~W}_{0.90}\right), 75 \% \mathrm{ET}_{0}\left(\mathrm{~W}_{0.75}\right)$, and $60 \% \mathrm{ET}_{0}$ $\left(\mathrm{W}_{0.60}\right)$. Based on the locally recommended nitrogen application amount of $300 \mathrm{~kg} \cdot \mathrm{hm}^{-2}\left(300 \mathrm{~kg} \cdot \mathrm{hm}^{-2}, \mathrm{~N}_{1.00}\right)$, three alternative regimes were tested with $75 \% \mathrm{~N}\left(225 \mathrm{~kg} \cdot \mathrm{hm}^{-2}\right.$, $\left.\mathrm{N}_{0.75}\right), 50 \%\left(150 \mathrm{~kg} \cdot \mathrm{hm}^{-2}, \mathrm{~N}_{0.50}\right)$, and 25\% $\left(75 \mathrm{~kg} \cdot \mathrm{hm}^{-2}, \mathrm{~N}_{0.25}\right)$. The test was designed to assess all 16 possible combinations of these variables, with three identical plots for each situation, reaching a total of 48 plots. Cultivation in furrows covered with film was adopted, which is typically used by local farmers. Each ridge had a height of $25 \mathrm{~cm}$ and width of $75 \mathrm{~cm}$. The top of the ridge was flat with spacing of $50 \mathrm{~cm}$ between ridges, plants were spaced at $45 \mathrm{~cm}$, and rows were separated by $30 \mathrm{~cm}$. Individual planting was used with a planting density of 31,000 plants per $\mathrm{hm}^{2}$. Each plot consists of one ridge with two plant rows. A drip lateral pipe was installed in the middle of two plant rows, so that one pipe controlled two rows. Each plot was $6.70 \times 1.25 \mathrm{~m}$, with a 
TABLE 1: Physical and chemical properties of the experimental field soil.

\begin{tabular}{lccccccccc}
\hline $\begin{array}{l}\text { Soil depth } \\
(\mathrm{cm})\end{array}$ & $\begin{array}{c}\text { Soil bulk } \\
\text { density } \\
\left(\mathrm{g} \cdot \mathrm{cm}^{-3}\right)\end{array}$ & $\begin{array}{c}\text { Field } \\
\text { capacity } \\
(\%)\end{array}$ & $\begin{array}{c}\text { Wilting } \\
\text { point } \\
(\%)\end{array}$ & $\begin{array}{c}\text { Saturated } \\
\text { moisture } \\
(\%)\end{array}$ & pH value & $\begin{array}{c}\text { Organic } \\
\text { matter } \\
\text { content } \\
(\%)\end{array}$ & $\begin{array}{c}\text { Total N } \\
\text { content } \\
(\%)\end{array}$ & $\begin{array}{c}\text { Total P } \\
\text { content } \\
(\%)\end{array}$ & $\begin{array}{c}\text { Total K } \\
\text { content } \\
(\%)\end{array}$ \\
\hline $0-20$ & 1.46 & 24.4 & 15.2 & 45.3 & 8.03 & 14.5 & 0.08 & 0.06 & 0.17 \\
$20-40$ & 1.57 & 23.8 & 18.2 & 42.0 & 8.15 & 15.7 & 0.08 & 0.05 & 0.14 \\
$40-60$ & 1.48 & 24.7 & 17.6 & 49.0 & 8.20 & 14.3 & 0.06 & 0.04 & 0.14 \\
$60-80$ & 1.45 & 25.2 & 16.0 & 35.2 & 8.20 & 14.0 & 0.05 & 0.02 \\
\hline
\end{tabular}

total area of $8.40 \mathrm{~m}^{2}$. To prevent the interaction of water and fertilizer between neighboring plots, the plots were separated by embedding plastic foil $1 \mathrm{~m}$ deep into the soil.

2.3. Irrigation and Fertilization. On January 6, 2014, seeds were soaked in water for 12 hours, followed by incubation in $1 \%$ copper sulfate solution for $5 \mathrm{~min}$, and subsequently washed with water. The seeds were then placed into a thermostat for germination from 25 to $30^{\circ} \mathrm{C}$ for ten days. The budding seeds were sowed in a hotbed. Five weeks later, the greenhouse was disinfected as follows. For each cubic meter of soil, $5 \mathrm{~g}$ sulfur, $0.1 \mathrm{~g} 80 \%$ insecticide (dichlorvos, 2,2dichlorovinyl dimethyl phosphate), and $10 \mathrm{~g}$ saw dust were mixed uniformly and ignited. After sealing the greenhouse overnight, the greenhouse was vented and sealed again. The elevated temperature of the greenhouse was continued for 48 hours. On April 1 and 2, the soil was prepared and basic fertilizer (phosphate) was applied. The seedlings, with 1 heart and from 8 to 12 leaves, were planted on the next day and uprooted on July 23. To ensure a proper seedling survival rate, $40 \mathrm{~mm}$ planting water was applied. Beginning from April 19, irrigation was conducted every five days. During the whole growth period, the total irrigation amounts for $\mathrm{W}_{1.05}, \mathrm{~W}_{0.90}, \mathrm{~W}_{0.75}$, and $\mathrm{W}_{0.60}$ were 263.1, 231.2, 199.4, and $167.8 \mathrm{~mm}$, respectively. After transplanting the seedlings, nitrogen was applied seven times, at day $20,40,55,65,75$, 85 , and 95, with amounts of 13.3, 13.3, 13.3, 20, 20, 13.3, and $6.7 \%$ of the total nitrogen amount applied to the whole growth period. After cultivation for 40 days, phosphate and potassium fertilizer was applied every 15 days for a total of five times, with application of $8.5 \mathrm{~kg} \cdot \mathrm{hm}^{-2}$ of phosphate fertilizer and $25 \mathrm{~kg} \cdot \mathrm{hm}^{-2}$ of potassium fertilizer each time. During the whole growth period, plant management such as support, pruning, and thinning was performed according to local custom.

\subsection{Measurements and Methods}

2.4.1. Dry Matter Content (DM). During the experiment, three $C$. annuum plants were randomly selected from each plot on 33, 54, 66, 81, and 112 days after transplanting (DAT) and the DM content of the plants (including stems, leaves, fruit, and roots) was determined. The plant material was dried by incubation at $105^{\circ} \mathrm{C}$ for $30 \mathrm{~min}$, followed by drying at $75^{\circ} \mathrm{C}$ until the weight was constant. The samples were then cooled in a dryer and weighed using a precision electronic scale. For each plot, the plant dry weight was expressed as the average of three plants, and the total biomass $\left(\mathrm{t} \cdot \mathrm{hm}^{-2}\right)$ was calculated by multiplying the dry weight with the planting density.

2.4.2. Chlorophyll Content. At the same time points that dry weight was determined, $0.1 \mathrm{~g}$ leaves were picked from randomly chosen plants for each plot. The third new leaf from the heart was selected, which grows rapidly. The amount of chlorophyll, comprised of chlorophyll a and chlorophyll b, was measured by a UV-Vis spectrophotometer (EV300PC, Thermo Fisher, USA) using an extraction method previously described [24].

2.4.3. Fruit Yield. During the ripening stage, red fruits in each test plot were picked every 10 days and weighed. The yields from each pick were added together to obtain the economic yield, and this was converted to $\mathrm{t} \cdot \mathrm{hm}^{-2}$. Three plants from each plot were marked and weighed, and the average yield per plant was calculated.

2.4.4. Fruit Quality. Ripe fruits with similar development characteristics were picked in each plot. The content of soluble solids in the fruits was measured as previously described [25] using an RHBO-90 hand refractometer (LINK, Co. Ltd., Taiwan China). The capsaicin content was measured by high performance liquid chromatography, and the vitamin $\mathrm{C}$ content was obtained by spectrometry using the molybdenum blue colorimetric method [24]. The soluble sugar content was measured by sulfuric acid anthrone colorimetry, and nitrate content was obtained using a UV-Vis spectrophotometer [19].

2.4.5. Water Use Efficiency. The water content in the soil was determined with a TDR moisture meter [26] and calibrated by traditional drying method. Two days before and after the test, the water content in the soil was measured every $10 \mathrm{~cm}$ up to a depth of $80 \mathrm{~cm}$.

The evapotranspiration (ET, $\mathrm{mm}$ ) of the plants at various stages was calculated by a water balance based on the reference [26]. There was no precipitation in greenhouse. The deep percolation and runoff were considered negligible, since the amount of water each time was less (the maximum value was about $24.1 \mathrm{~mm}$ ). The equation used to calculate ET is

$$
\mathrm{ET}=I-\Delta W,
$$

where $I$ is the irrigation amount $(\mathrm{mm})$ and $\Delta W$ is the water variation $(\mathrm{mm})$ in the initial and final soil. 
The irrigation amount $I$ can be calculated as follows:

$$
I=K_{c} \cdot \mathrm{ET}_{0}
$$

where $K_{c}$ is the crop coefficient which was based on FAO56 [27] and $K_{c \text { ini }}, K_{c \text { mid }}$, and $K_{c \text { end }}$ were $0.60,1.05$, and 0.90 , respectively.

In the greenhouse evaporation and heat transfer still occur, even in the absence of wind, since the air boundary layer is a nonneutral stable layer. $\mathrm{ET}_{0}$ was calculated according to the modified Penman-Monteith equation for a sunlight greenhouse, as published previously [28]. Meteorological data for calculating $\mathrm{ET}_{0}$ were taken from the weather station inside the greenhouse.

$$
\begin{aligned}
& \mathrm{ET}_{0}(P-M) \\
& =\frac{0.408 \Delta\left(R_{n}-G\right)+\gamma\left(1713\left(e_{a}-e_{d}\right) /(T+273)\right)}{\Delta+1.64 \gamma},
\end{aligned}
$$

where $\mathrm{ET}_{0}$ is the referenced crop evapotranspiration $\left(\mathrm{mm} \cdot \mathrm{d}^{-1}\right), R_{n}$ is the surface net radiation $\left(\mathrm{MJ} \cdot \mathrm{m}^{-2} \cdot \mathrm{d}^{-1}\right), G$ is the soil heat flux $\left(\mathrm{MJ} \cdot \mathrm{m}^{-2} \cdot \mathrm{d}^{-1}\right), e_{a}$ is the saturated vapor pressure $(\mathrm{kPa}), e_{d}$ is the actual vapor pressure $(\mathrm{kPa}), \Delta$ is the slope of saturated vapor pressure curve $\left(\mathrm{kPa} \cdot{ }^{\circ} \mathrm{C}^{-1}\right), \gamma$ is the dry wet constant $\left(\mathrm{kPa} \cdot{ }^{\circ} \mathrm{C}^{-1}\right)$, and $T$ is the average temperature at $2 \mathrm{~m}\left({ }^{\circ} \mathrm{C}\right)$. [29]:

The water use efficiency WUE is calculated as follows

$$
\mathrm{WUE}=\frac{Y}{(\mathrm{ET} * 10)},
$$

where $Y$ is the yield in $\mathrm{kg} \cdot \mathrm{hm}^{-2}$.

2.4.6. Partial Factor Productivity from Applied Nitrogen. The partial factor productivity from applied nitrogen (PFPN) can be calculated as follows [30]:

$$
\mathrm{PFPN}=\frac{Y}{F},
$$

where $F$ is the total mass of applied nitrogen $\left(\mathrm{kg} \cdot \mathrm{hm}^{-2}\right)$.

2.5. Data Analysis. Statistical analysis software including Excel 2010 and SPSS Statistics 18.0 was used to analyze the experimental data. Duncan's new multiple range test method was employed for multiple comparisons. If a significant difference was observed $(P<0.05)$, Tukey HSD comparison was adopted. All figures were plotted using Origin 8.0 software.

\section{Results}

3.1. Influence of Water-Nitrogen Regimes on Dry Matter Content of C. annuum. Growth of C. annuum plants was followed during the course of the experiment by determining dry matter content (DM) at various time points, as shown in Figure 1. The DM initially increased rapidly, followed by a slower increase at later stages. Fifty-four days after planting, DM starts to show increasing differences between the tested conditions. As expected, DM is affected by the amount of $\mathrm{N}$ supplied to the plants. According to the slopes of the curves (Figure 1), under the same irrigation regime, the increase of DM is more rapid at $\mathrm{N}_{0.75}$ and $\mathrm{N}_{0.50}$ than at $\mathrm{N}_{1.00}$, while $\mathrm{N}_{0.25}$ produced the slowest increase in dry weight.

The average DM at the highest irrigation level applied $\left(\mathrm{W}_{1.05}\right)$ varies from 1.73 to $12.50 \mathrm{t} \cdot \mathrm{hm}^{-2}$ at $54-112$ days. For $\mathrm{W}_{0.90}$ this variation is $0.96-1.15$ times that of $\mathrm{W}_{1.05}$, for $\mathrm{W}_{0.75}$ it is $0.91-1.05$ times that of $W_{1.05}$, and at $W_{0.60}$ (least irrigation) the variation of average DM is only $0.78-0.76$ times that of $\mathrm{W}_{1.05}$. Thus, compared to $\mathrm{W}_{1.05}$, irrigation levels $\mathrm{W}_{0.90}$ and $\mathrm{W}_{0.75}$ resulted in a more rapid DM increase in the middle and end growth stage, while $\mathrm{W}_{0.60}$ suppressed DM increase during the complete growth period. This indicates that, under limited water stress (irrigation levels $\mathrm{W}_{0.90}$ and $\mathrm{W}_{0.75}$ ), crop yield is promoted, resulting in a DM increase during the middle and end growth stage.

Keeping the nitrogen supply constant, the DM exhibits first an increase and then a decrease with increasing irrigation levels. At harvest time, the DM of $\mathrm{N}_{0.75}, \mathrm{~N}_{0.50}$, and $\mathrm{N}_{0.25}$ is $1.12,1.03$, and 0.84 times that of $\mathrm{N}_{1.00}$, suggesting that the applied nitrogen amounts in $\mathrm{N}_{0.75}$ and $\mathrm{N}_{0.50}$ are favorable for higher DM. Thus, for both irrigation and nitrogen levels, the DM first increases followed by a decrease. At harvest time, samples with DM above $13.0 \mathrm{t} \cdot \mathrm{hm}^{-2}$ include the combinations $\mathrm{W}_{1.05} \mathrm{~N}_{0.75}, \mathrm{~W}_{1.05} \mathrm{~N}_{0.50}, \mathrm{~W}_{0.90} \mathrm{~N}_{0.75}, \mathrm{~W}_{0.90} \mathrm{~N}_{0.50}, \mathrm{~W}_{0.75} \mathrm{~N}_{0.75}$, and $\mathrm{W}_{0.75} \mathrm{~N}_{0.50}$. These conditions resulted in an increase of DM of 7.77, 2.61, 9.82, 6.37, 7.22, and 3.03\%, respectively, compared to the control $\left(\mathrm{W}_{1.05} \mathrm{~N}_{1.00}, \mathrm{DM}\right.$ of $\left.12.87 \mathrm{t} \cdot \mathrm{hm}^{-2}\right)$ which represents local conventional irrigation and nitrogen application.

3.2. Influence of Water-Nitrogen Regimes on Chlorophyll Content. Chlorophyll content in the leaves was determined to provide a measure of the growth status of the plants. Chlorophyll is required for photosynthesis to produce sugars that enable growth, but a high chlorophyll content in the leaves can be disadvantageous for fruit production, when the plants favor growth of parts other than fruit.

During growth, the overall chlorophyll content in the leaves first increased, followed by a decrease (Figure 2). Comparing conditions with the same irrigation level (individual curves within a panel) showed that the chlorophyll content increased with nitrogen levels. However, when the nitrogen level was kept constant (comparing curves with the same color), an increase in irrigation resulted first in an increase and then in a decrease of the chlorophyll content in leaves. According to the slope of the curve obtained, $\mathrm{W}_{0.90}$ and $\mathrm{W}_{0.75}$ had the largest influence on chlorophyll content compared to $\mathrm{W}_{1.05}$. Particularly between days 54 and 61 a rapid increase was observed. This phase corresponds to the flowering, fruiting, and reproductive stages of the plant. The products of photosynthesis are mainly reserved for growth of stems, leaves, and fruits, and these plant parts may compete with each other. Under various irrigation levels, control fertilizer level $\mathrm{N}_{1.00}$ resulted in a high leave chlorophyll content during the entire fruiting stage (Figure 2). Under this nitrogen supply level, a large number of small fruits developed which, after 


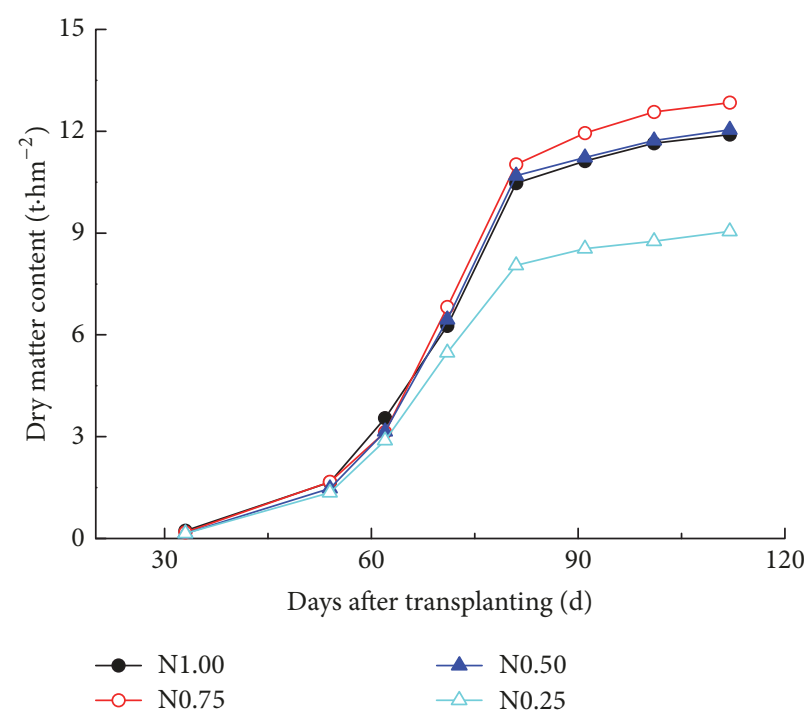

(a) $\mathrm{W}_{1.05}$ treatment

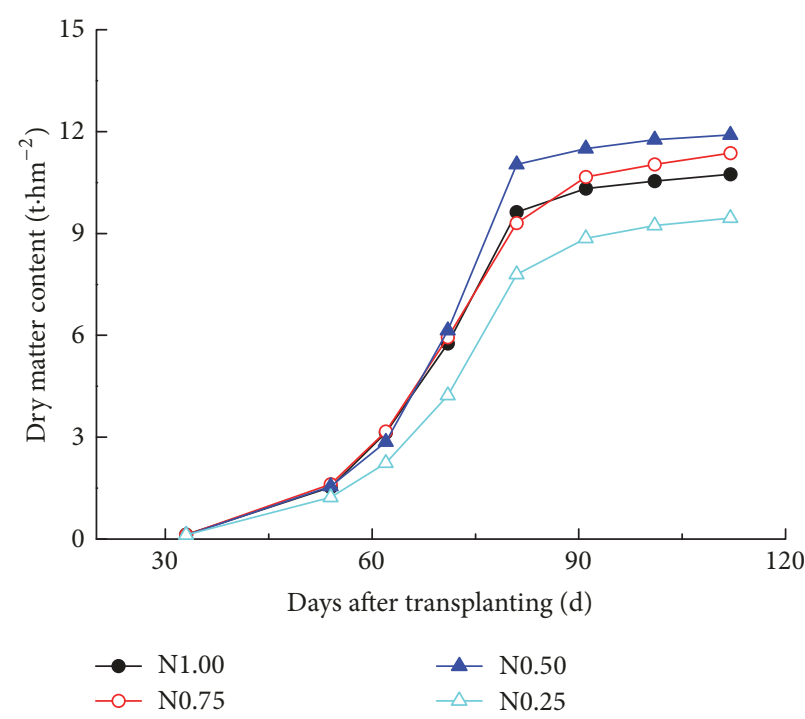

(c) $\mathrm{W}_{0.75}$ treatment

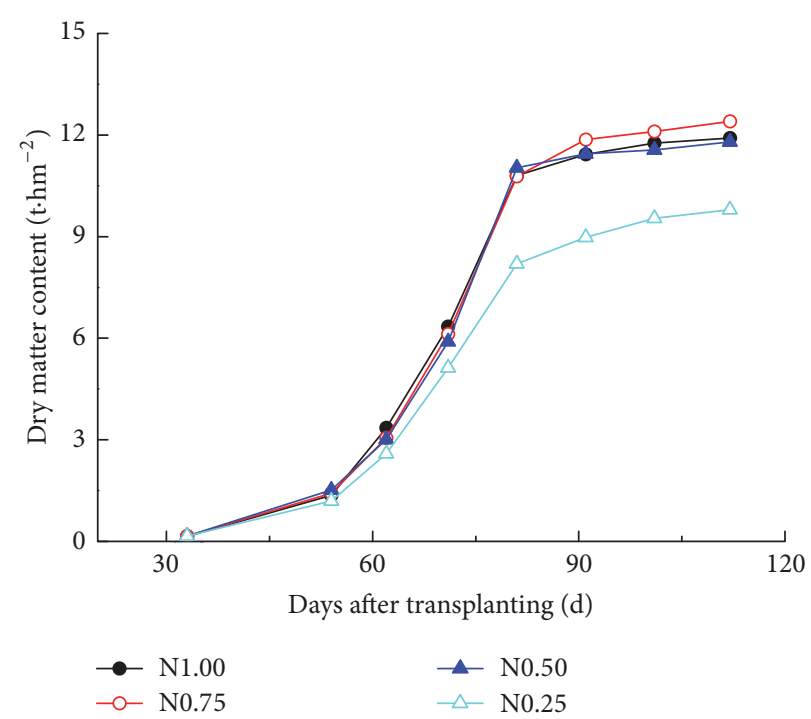

(b) $\mathrm{W}_{0.90}$ treatment

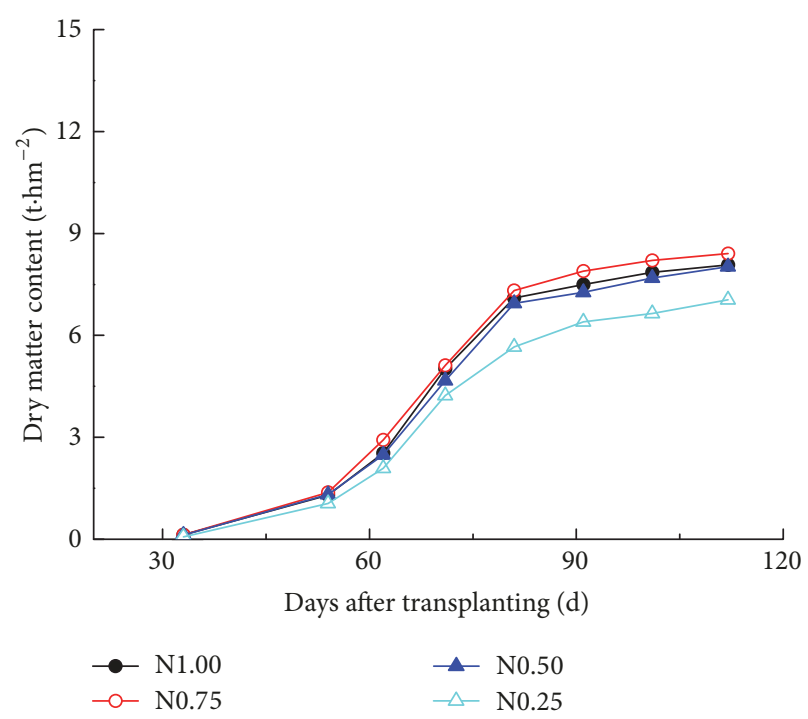

(d) $\mathrm{W}_{0.60}$ treatment

Figure 1: Effects of different water and nitrogen levels on dry matter content of greenhouse sweet pepper. Panel (a) shows treatment $\mathrm{W}_{105}$ corresponding to an irrigation of $105 \%$ of the reference crop evapotranspiration $\mathrm{ET}_{0}$, panel (b) shows treatment $\mathrm{W}_{0.90}$, panel (c) shows $\mathrm{W}_{0.75}$, and panel $(\mathrm{d})$ shows treatment $\mathrm{W}_{0.60}\left(60 \% \mathrm{ET}_{0}\right)$. The black curves represent treatment $\mathrm{N}_{1.00}\left(100 \%\right.$ of recommended $\mathrm{N}$ fertilizer, $\left.300 \mathrm{~kg} \cdot \mathrm{hm}{ }^{-2}\right)$, red curves show $\mathrm{N}_{0.75}$, blue shows $\mathrm{N}_{0.50}$, and light green shows $\mathrm{N}_{0.25}$ (5\% of recommended $\mathrm{N}$ fertilizer).

thinning, resulted in fewer nutrients being distributed to the fruits, allowing the stem and leaves to grow vigorously. In contrast, the condition $\mathrm{W}_{0.60} \mathrm{~N}_{0.25}$ produced fewer fruits, suggesting that low water and nitrogen supplies resulted in an imbalance of resources, accelerating leaf aging and resulting in low chlorophyll content. As can be seen in Figures 2(b) and 2(c), under conditions $\mathrm{W}_{0.90} \mathrm{~N}_{0.75}, \mathrm{~W}_{0.90} \mathrm{~N}_{0.50}, \mathrm{~W}_{0.75} \mathrm{~N}_{0.75}$, and $\mathrm{W}_{0.75} \mathrm{~N}_{0.50}$ the chlorophyll content increased fastest to give maximum levels at day 54, indicating that limited water stress and nitrogen application can promote the allocation of nutrients to the fruits and this can accelerate fruit growth.

Towards the end of the fruiting stage the chlorophyll content of leaves was shown to increase, independent of the fertigation regime (Figure 2). This is because the perennial plant quickly develops to the next growth period after ripe fruit has been picked.

3.3. Influence of Water-Nitrogen Regimes on Fruit Yield and Water Usage. The influence of various irrigation and nitrogen supply combinations on economic yield, WUE, and PFPN is shown in Table 2. As can be seen, water and nitrogen levels have a significant $(P<0.01)$ impact on fruit yield, WUE, and PFPN.

Under the same irrigation condition, an increase of nitrogen level resulted in an initial increase in the economic yield and WUE, followed by decrease, while PFPN decreased 


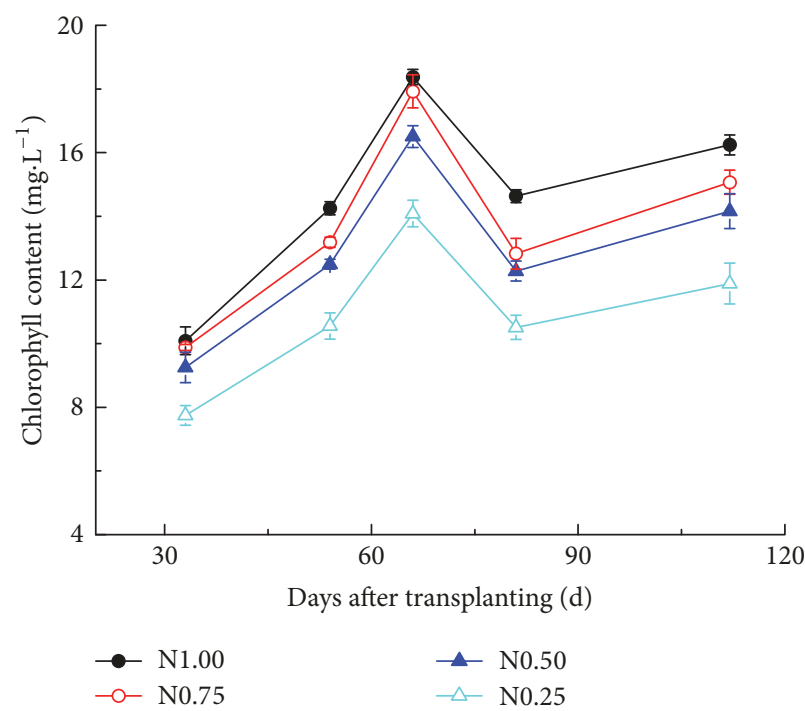

(a) $\mathrm{W}_{1.05}$ treatment

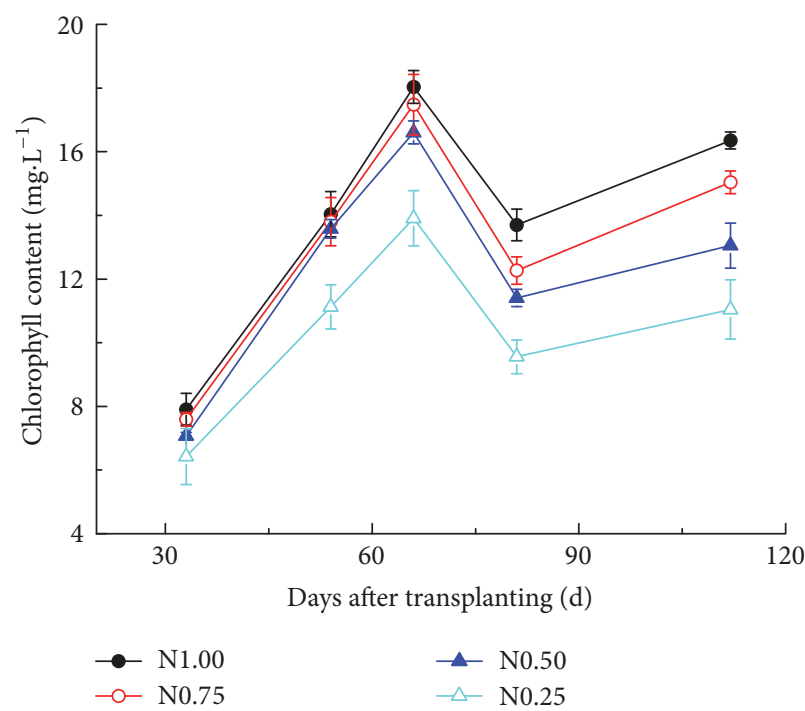

(c) $\mathrm{W}_{0.75}$ treatment

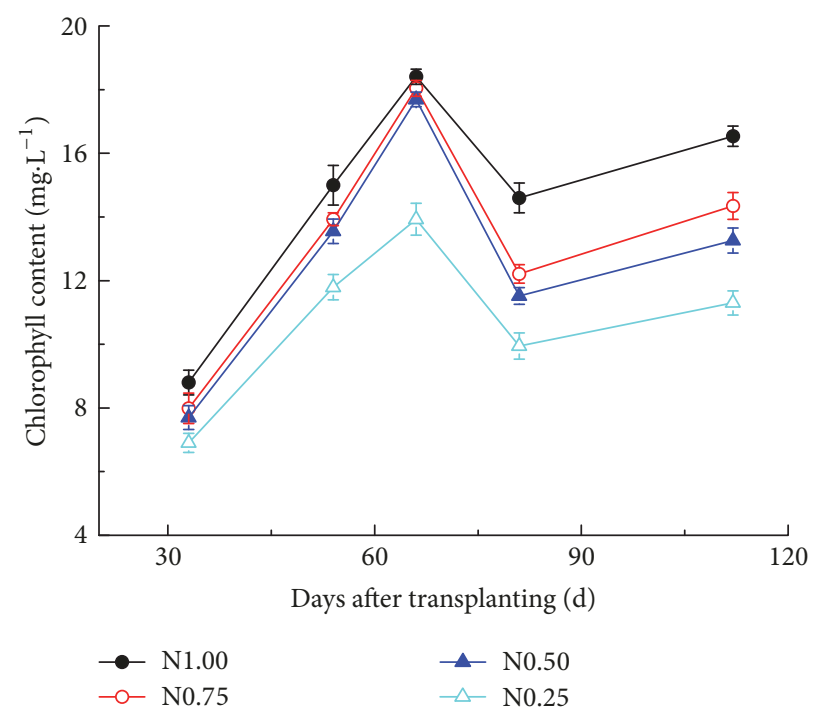

(b) $\mathrm{W}_{0.90}$ treatment

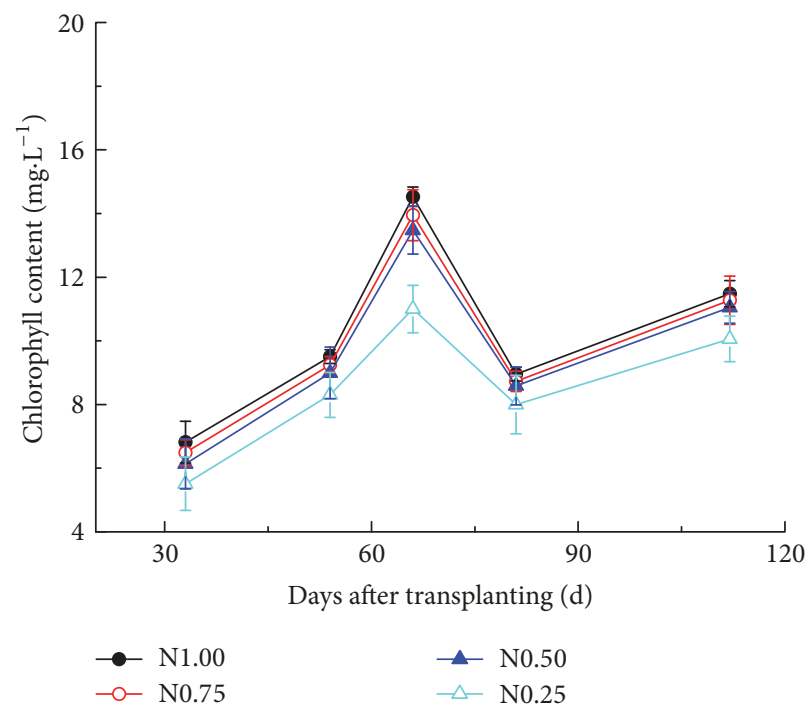

(d) $\mathrm{W}_{0.60}$ treatment

FIGURE 2: Effects of different water and nitrogen levels on chlorophyll content of greenhouse sweet pepper. The codes for treatment and color use are as described for Figure 1.

(Table 2). Compared to the control water supply $\mathrm{W}_{1.05}$, the economic yield of $\mathrm{W}_{0.90}$ increased by $9.64 \%$ and that of $\mathrm{W}_{0.75}$ by $2.53 \%$, while for these conditions WUE increased by 23.04 and $33.44 \%$, respectively. In contrast, the economic yield of $\mathrm{W}_{0.60}$ decreased by $34.23 \%$, with WUE increasing by $5.28 \%$. Compared to $\mathrm{W}_{1.05}$, the PFPN of $\mathrm{W}_{0.90}$ increased by $7.22 \%$, whereas for $\mathrm{W}_{0.60}$ it decreased by $35.89 \%\left(\mathrm{~W}_{0.75}\right.$ showed little difference to the control). Under the same nitrogen level and an increase of irrigation, the economic yield, WUE, and PFPN initially increased followed by a decrease. Compared to nitrogen level $\mathrm{N}_{1.00}$, under conditions $\mathrm{N}_{0.75}$ and $\mathrm{N}_{0.50}$, the economic yield increased by 37.68 and $35.54 \%$, respectively, while WUE increased by 35.74 and $33.67 \%$ respectively. In contrast, $\mathrm{N}_{0.25}$ only resulted in marginal increases of these parameters. Compared to $\mathrm{N}_{1.00}$, the PFPN of $\mathrm{N}_{0.75}$ and $\mathrm{N}_{0.50}$ increased by 80.46 and $166.52 \%$. For $\mathrm{N}_{0.25}$ this increase was as high as $301.94 \%$.

In combination, these results indicate that moderate water supply $\left(\mathrm{W}_{0.90}\right.$ and $\left.\mathrm{W}_{0.75}\right)$ and limited nitrogen application $\left(\mathrm{N}_{0.75}\right.$ and $\left.\mathrm{N}_{0.50}\right)$ promote the forming of the fruit resulting in higher yields, while improving WUE. Overly high levels of water $\left(\mathrm{W}_{1.05}\right)$ and nitrogen $\left(\mathrm{N}_{1.00}\right)$ supply can promote plant growth to a certain extent, but excessive growth results in reduced economic yields. Strong water stress $\left(\mathrm{W}_{0.60}\right)$ and nitrogen stress $\left(\mathrm{N}_{0.25}\right)$ are insufficient for optimal plant growth, leading to low DM (Figure 1) and low economic yields. Thus, compared to the control, $\mathrm{W}_{1.05} \mathrm{~N}_{0.75}, \mathrm{~W}_{1.05} \mathrm{~N}_{0.50}$, $\mathrm{W}_{0.90} \mathrm{~N}_{0.75}, \mathrm{~W}_{0.90} \mathrm{~N}_{0.50}, \mathrm{~W}_{0.75} \mathrm{~N}_{0.75}$, and $\mathrm{W}_{0.75} \mathrm{~N}_{0.50}$ resulted in improved economic yields, with an increase of 12.39, 6.47, $20.16,14.38,17.13$, and $15.22 \%$, respectively. In terms of WUE, 
TABLE 2: Effects of different water and nitrogen levels on sweet pepper: marketable yield and WUE.

\begin{tabular}{|c|c|c|c|c|}
\hline Irrigation treatment & Nitrogen treatment & Market yield $\left(\mathrm{t} \cdot \mathrm{hm}^{-2}\right)$ & WUE $\left(\mathrm{kg} \cdot \mathrm{m}^{-3}\right)$ & PFPN $\left(\mathrm{kg} \cdot \mathrm{kg}^{-1}\right)$ \\
\hline \multirow{4}{*}{$\mathrm{W}_{1.05}$} & $\mathrm{~N}_{1.00}$ & $22.19^{\mathrm{de}}$ & $8.97^{\mathrm{f}}$ & $73.96^{\mathrm{d}}$ \\
\hline & $\mathrm{N}_{0.75}$ & $30.28^{c}$ & $11.48^{\mathrm{de}}$ & $126.16^{\mathrm{c}}$ \\
\hline & $\mathrm{N}_{0.50}$ & $31.51^{\mathrm{bc}}$ & $11.95^{\mathrm{de}}$ & $196.96^{\mathrm{c}}$ \\
\hline & $\mathrm{N}_{0.25}$ & $24.11^{\mathrm{de}}$ & $9.14^{\mathrm{f}}$ & $301.32^{\mathrm{d}}$ \\
\hline \multirow{4}{*}{$\mathrm{W}_{0.90}$} & $\mathrm{~N}_{1.00}$ & $25.50^{\mathrm{d}}$ & $11.00^{\mathrm{e}}$ & $79.69^{c}$ \\
\hline & $\mathrm{N}_{0.75}$ & $34.85^{\mathrm{a}}$ & $15.03^{\mathrm{b}}$ & $145.19^{\mathrm{ab}}$ \\
\hline & $\mathrm{N}_{0.50}$ & $32.48^{\mathrm{ab}}$ & $14.01^{\mathrm{c}}$ & $203.00^{\mathrm{b}}$ \\
\hline & $\mathrm{N}_{0.25}$ & $25.68^{\mathrm{d}}$ & $11.07^{\mathrm{e}}$ & $320.95^{\mathrm{c}}$ \\
\hline \multirow{4}{*}{$\mathrm{W}_{0.75}$} & $\mathrm{~N}_{1.00}$ & $23.03^{e}$ & $11.52^{\mathrm{de}}$ & $71.95^{\mathrm{c}}$ \\
\hline & $\mathrm{N}_{0.75}$ & $32.99^{\mathrm{ab}}$ & $16.50^{\mathrm{a}}$ & $137.45^{\mathrm{a}}$ \\
\hline & $\mathrm{N}_{0.50}$ & $31.63^{\mathrm{bc}}$ & $15.82^{\mathrm{ab}}$ & $197.67^{\mathrm{a}}$ \\
\hline & $\mathrm{N}_{0.25}$ & $23.17^{\mathrm{e}}$ & $11.59^{\mathrm{de}}$ & $289.57^{\mathrm{c}}$ \\
\hline \multirow{4}{*}{$\mathrm{W}_{0.50}$} & $\mathrm{~N}_{1.00}$ & $15.20^{\mathrm{g}}$ & $9.05^{\mathrm{f}}$ & $47.51^{\mathrm{d}}$ \\
\hline & $\mathrm{N}_{0.75}$ & $20.18^{\mathrm{f}}$ & $12.02^{\mathrm{de}}$ & $84.08^{\mathrm{c}}$ \\
\hline & $\mathrm{N}_{0.50}$ & $20.84^{\mathrm{f}}$ & $12.41^{\mathrm{d}}$ & $130.26^{\mathrm{c}}$ \\
\hline & $\mathrm{N}_{0.25}$ & $14.87^{\mathrm{g}}$ & $8.86^{\mathrm{f}}$ & $185.90^{\mathrm{d}}$ \\
\hline \multicolumn{5}{|c|}{ Significance level ( $F$ value) } \\
\hline Irrigation & & $220.77^{* *}$ & $220.77^{* *}$ & $2.60^{*}$ \\
\hline Nitrogen & & $103.34^{* *}$ & $103.34^{*}$ & $2.88^{*}$ \\
\hline Irrigation $\times$ nitrogen & & $126.29^{* *}$ & $126.29^{* *}$ & $10.93^{*}$ \\
\hline
\end{tabular}

Statistical significance is shown as superscripts, with different superscripts indicating significant $(P<0.05)$ differences within a parameter under constant irrigation. At the bottom of the table, significance $F$ values are indicated with ${ }^{* *} P$ value 0.001 and ${ }^{*} P$ value 0.05 .

$\mathrm{W}_{0.90} \mathrm{~N}_{0.75}, \mathrm{~W}_{0.90} \mathrm{~N}_{0.50}, \mathrm{~W}_{0.75} \mathrm{~N}_{0.75}$, and $\mathrm{W}_{0.75} \mathrm{~N}_{0.50}$ resulted in an increase of $36.72,30.15,54.59$, and $52.06 \%$, respectively. Finally, again compared to the control, the PFPN increased by $60.21,128.76,56.18$, and $130.43 \%$, respectively. Overall, $\mathrm{W}_{0.75} \mathrm{~N}_{0.75}$ treatment provided the optimal combination for enhanced economic yield and improved WUE and PFPN simultaneously. Similar economic yields were obtained with $\mathrm{W}_{0.90} \mathrm{~N}_{0.75}, \mathrm{~W}_{0.90} \mathrm{~N}_{0.50}$, and $\mathrm{W}_{0.75} \mathrm{~N}_{0.50}$, though the other parameters were suboptimal. Likewise, water use was also efficient in $\mathrm{W}_{0.75} \mathrm{~N}_{0.50}$, and PFPN of $\mathrm{W}_{0.90} \mathrm{~N}_{0.50}$ was similar to the optimal condition $\mathrm{W}_{0.75} \mathrm{~N}_{0.75}$.

3.4. Influence of Water-Nitrogen Regimes on the Quality of the Produce. The influence of water and nitrogen on the content of soluble sugar, capsaicin, vitamin $\mathrm{C}\left(\mathrm{V}_{\mathrm{c}}\right)$, nitrates, and soluble solids in the fruits is shown in Table 3 . The tested regimes had a strong impact on the quality indexes $(P<$ $0.01)$, and $\mathrm{V}_{\mathrm{c}}$ content was also significantly affected $(P<$ 0.05). Comparing increasing nitrogen levels with a constant water supply, the content of soluble sugars, $\mathrm{V}_{\mathrm{c}}$, and soluble solids first increased and then decreased, while capsaicin and nitrates contents both increased. Under the same nitrogen level, an increase of irrigation resulted in a decrease in soluble sugar and nitrates content, while $\mathrm{V}_{\mathrm{c}}$ content first increased and then decreased, and capsaicin and soluble solids contents both increased.

The contents of soluble sugars, capsaicin, $\mathrm{V}_{\mathrm{c}}$, and soluble solids provide important indexes of fruit quality, as they determine the nutritional value and flavor. A lower nitrate content of vegetables is generally preferred, whereas greenhouse cultures have a higher nitrogen content than openair cultures (Liao et al., 2011). Five indexes were calculated to assess the nutritional value of the produced fruit: soluble sugar $\left(X_{1}\right)$, capsaicin $\left(X_{2}\right), \mathrm{V}_{\mathrm{c}}\left(X_{3}\right)$, nitrates $\left(X_{4}\right)$, and soluble solids $\left(X_{5}\right)$ using SPSS 18 software. The calculated contribution ratio for each index is as follows: soluble sugar: 42.851\%, capsaicin: $28.923 \%, \mathrm{~V}_{\mathrm{c}}: 20.569 \%$, nitrates: $5.779 \%$, and soluble solids: $1.879 \%$. The former three indexes contribute $92.342 \%$ of the total index. Thus, these three main contents were used, and the corresponding characterization values produced were $\lambda_{1}=2.143, \lambda_{2}=1.446$, and $\lambda_{3}=1.028$, respectively.

By calculation, the main content can be expressed as follows:

First main content: $F_{1}=0.683 X_{1}-0.288 X_{2}+$ $0.298 X_{3}+0.105 X_{4}-0.393 X_{5}$

Second main content: $F_{2}=-0.351 X_{1}+0.832 X_{2}+$ $0.368 X_{3}+0.046 X_{4}+0.579 X_{5}$

Third main content: $F_{3}=0.431 X_{1}+0.436 X_{2}+$ $0.986 X_{3}-0.084 X_{4}+0.038 X_{5}$.

Using the ratio of each characterization value to the sum of the values as a weighing factor, a comprehensive evaluation function was established that calculated the quality of the produced fruits, given as $F=0.464 F_{1}+0.313 F_{2}+0.223 F_{3}$. Higher scores calculated with this function indicate better fruit quality. 
TABLE 3: Effects of different water and nitrogen levels on fruit quality.

\begin{tabular}{|c|c|c|c|c|c|c|}
\hline $\begin{array}{l}\text { Irrigation } \\
\text { treatment }\end{array}$ & $\begin{array}{l}\text { Nitrogen } \\
\text { Treatment }\end{array}$ & Soluble sugar\%o & Capsaicin\%o & $\mathrm{V}_{\mathrm{c}} \% \mathrm{o}$ & Nitrate\%o & Soluble solids $\%$ \\
\hline \multirow{4}{*}{$\mathrm{W}_{1.05}$} & $\mathrm{~N}_{1.00}$ & $23.55^{\mathrm{h}}$ & $0.23^{\mathrm{a}}$ & $25.88^{\mathrm{de}}$ & $0.42^{\mathrm{cd}}$ & $7.85^{\mathrm{ab}}$ \\
\hline & $\mathrm{N}_{0.75}$ & $26.44^{\mathrm{gh}}$ & $0.22^{\mathrm{ab}}$ & $29.88^{\mathrm{cd}}$ & $0.35^{\text {def }}$ & $7.40^{\text {bcdef }}$ \\
\hline & $\mathrm{N}_{0.50}$ & $30.56^{\mathrm{def}}$ & $0.22^{\mathrm{abc}}$ & $32.94^{\mathrm{bc}}$ & $0.31^{\text {efg }}$ & $7.60^{\mathrm{abc}}$ \\
\hline & $\mathrm{N}_{0.25}$ & $26.13^{\text {gh }}$ & $0.19^{\mathrm{cdf}}$ & $26.05^{\mathrm{de}}$ & $0.23^{\mathrm{g}}$ & $7.50^{\text {abcde }}$ \\
\hline \multirow{4}{*}{$\mathrm{W}_{0.90}$} & $\mathrm{~N}_{1.00}$ & $27.2^{\mathrm{hi}}$ & $0.20^{\mathrm{abcd}}$ & $27.81^{\text {cde }}$ & $0.45^{\mathrm{c}}$ & $7.95^{\mathrm{a}}$ \\
\hline & $\mathrm{N}_{0.75}$ & $32.34^{\mathrm{d}}$ & $0.21^{\mathrm{abc}}$ & $30.31^{\mathrm{cd}}$ & $0.35^{\text {def }}$ & $7.55^{\mathrm{abcd}}$ \\
\hline & $\mathrm{N}_{0.50}$ & $35.87^{\mathrm{c}}$ & $0.21^{\mathrm{abc}}$ & $42.24^{\mathrm{a}}$ & $0.33^{\text {def }}$ & $7.05^{\text {defg }}$ \\
\hline & $\mathrm{N}_{0.25}$ & $27.96^{\text {efg }}$ & $0.19^{\text {cdf }}$ & $25.47^{\text {de }}$ & $0.21^{\mathrm{g}}$ & $7.35^{\text {bcdef }}$ \\
\hline \multirow{4}{*}{$\mathrm{W}_{0.75}$} & $\mathrm{~N}_{1.00}$ & $29.51^{\text {defg }}$ & $0.21^{\mathrm{abc}}$ & $28.45^{\text {cde }}$ & $0.67^{\mathrm{a}}$ & $7.25^{\text {cdef }}$ \\
\hline & $\mathrm{N}_{0.75}$ & $37.19^{\mathrm{bc}}$ & $0.20^{\mathrm{bcd}}$ & $36.38^{\mathrm{b}}$ & $0.47^{\mathrm{c}}$ & $7.20^{\operatorname{defg}}$ \\
\hline & $\mathrm{N}_{0.50}$ & $39.27^{\mathrm{bc}}$ & $0.21^{\mathrm{abc}}$ & $46.53^{\mathrm{a}}$ & $0.35^{\text {def }}$ & $7.04^{\text {defg }}$ \\
\hline & $\mathrm{N}_{0.25}$ & $31.13^{\mathrm{de}}$ & $0.17^{\mathrm{f}}$ & $25.39^{\mathrm{de}}$ & $0.25^{\mathrm{fg}}$ & $6.80^{\mathrm{h}}$ \\
\hline \multirow{4}{*}{$\mathrm{W}_{0.60}$} & $\mathrm{~N}_{1.00}$ & $30.80^{\text {def }}$ & $0.19^{\mathrm{cdf}}$ & $23.67^{\mathrm{e}}$ & $0.70^{\mathrm{a}}$ & $6.95^{\text {fgh }}$ \\
\hline & $\mathrm{N}_{0.75}$ & $40.10^{\mathrm{b}}$ & $0.18^{\mathrm{df}}$ & $26.79^{\mathrm{de}}$ & $0.57^{\mathrm{b}}$ & $7.00^{\text {efgh }}$ \\
\hline & $\mathrm{N}_{0.50}$ & $44.67^{\mathrm{a}}$ & $0.16^{\mathrm{f}}$ & $30.55^{\mathrm{cd}}$ & $0.40^{\text {cde }}$ & $6.85^{\mathrm{gh}}$ \\
\hline & $\mathrm{N}_{0.25}$ & $31.93^{\mathrm{d}}$ & $0.15^{\mathrm{f}}$ & $18.91^{\mathrm{f}}$ & $0.31^{\text {efg }}$ & $6.20^{\mathrm{i}}$ \\
\hline \multicolumn{7}{|c|}{ Significance level ( $F$ value $)$} \\
\hline \multicolumn{2}{|c|}{ Irrigation } & $57.86^{*}$ & $15.96^{* *}$ & $24.81^{* *}$ & $26.78^{* *}$ & $27.3^{* *}$ \\
\hline \multicolumn{2}{|l|}{ Nitrogen } & $59.77^{* *}$ & $9.12^{* *}$ & $61.32^{* *}$ & $71.81^{* *}$ & $9.1^{* *}$ \\
\hline \multicolumn{2}{|c|}{ Irrigation $\times$ nitrogen } & $2.53^{*}$ & 0.8 & $3.67^{* *}$ & $3.27^{*}$ & 2.09 \\
\hline
\end{tabular}

Significance is indicated as for Table 2.

The results (Table 4) show that, under the same nitrogen level, $\mathrm{W}_{0.75}$ resulted in the highest average score, followed by $\mathrm{W}_{0.90}$ and $\mathrm{W}_{1.05}$, while $\mathrm{W}_{0.60}$ produced the lowest score. Under the same irrigation condition, $\mathrm{N}_{0.50}$ gave the highest score, followed by $\mathrm{N}_{0.75}$ and $\mathrm{N}_{1.00}\left(\mathrm{~N}_{0.25}\right.$ was the lowest). These results again indicate that moderate irrigation $\left(\mathrm{W}_{0.90}\right.$ and $\left.\mathrm{W}_{0.75}\right)$ and nitrogen $\left(\mathrm{N}_{0.75}\right.$ and $\left.\mathrm{N}_{0.50}\right)$ levels are favorable for nutrients absorption into the fruits. Particularly, the soluble sugar and $\mathrm{V}_{\mathrm{c}}$ content in the fruit can be increased using these regimes.

The conditions were ranked for the obtained scores, which placed the control at the 11th position. The top six scores were obtained with $\mathrm{W}_{0.75} \mathrm{~N}_{0.50}$ (score value 1.64), $\mathrm{W}_{0.90} \mathrm{~N}_{0.50}$ (1.22), $\mathrm{W}_{0.75} \mathrm{~N}_{0.75}$ (0.79), $\mathrm{W}_{0.60} \mathrm{~N}_{0.50}$ (0.40), $\mathrm{W}_{1.05} \mathrm{~N}_{0.50}(0.35)$, and $\mathrm{W}_{0.90} \mathrm{~N}_{0.75}(0.22)$. The lowest score observed (-1.16) was obtained with $\mathrm{W}_{0.60} \mathrm{~N}_{0.25}$. This once more shows that $\mathrm{W}_{0.75} \mathrm{~N}_{0.50}, \mathrm{~W}_{0.90} \mathrm{~N}_{0.50}$, and $\mathrm{W}_{0.75} \mathrm{~N}_{0.75}$ represent favorable conditions for greenhouse culture of $C$. annuum, here assessed for parameters determined by the absorption of nutrients into the fruits.

\section{Discussion}

Adjustment of water and fertilizer supplies is the basis of optimizing agricultural practices and facility management. Proper water management and nitrogen control can improve crop growth significantly, resulting in increased economic yields, more efficient water use, and higher quality produce with lower investment costs and higher output. Conversely, poor management of water and fertilizer can lead to increased costs, wasted use of water and nitrogen resources, and negative effects on the leaf area index of crops as well as final yields [31]. Nitrogen is of particular importance, as it directly affects vegetable growth and fruit development. Proper waternitrogen management can improve the photosynthetic assimilation of the plants and the quality of the produce [10]. The fertigation technique can provide crops with optimal supplies of water and nutrients [17, 19-21, 32]. Based on previous research, we assessed in detail the influence of water and nitrogen supplies on the growth, photosynthesis, economic yield, WUE, PFPN, and quality of C. annuum fruit in order to define the optimal conditions for greenhouse culture of this economically important produce.

The results have identified that conditions of water levels $\mathrm{W}_{0.90}$ and $\mathrm{W}_{0.75}$ (90 and $75 \% \mathrm{ET}_{0}$, resp.), in combination with nitrogen levels $\mathrm{N}_{0.75}$ and $\mathrm{N}_{0.50}\left(225\right.$ and $150 \mathrm{~kg} \cdot \mathrm{hm}^{-2}$, resp.), provide an optimal window. A moderate water stress and limited nitrogen supplies promote the growth and development of fruit and result in a favorable increase of chlorophyll in the leaves, which in turn is responsible for an increase in DM. These results are in accordance with previously recorded observations [11, 23, 33]. Under the test conditions, the optimized water and nitrogen levels avoid excessive water and fertilizer use, while supporting proper growth and development. In contrast to our findings, Ayodele and colleagues concluded that the DM content of 
TABLE 4: Evaluation of fruit quality under different water and nitrogen levels by multiple component analysis.

\begin{tabular}{lcccccc}
\hline $\begin{array}{l}\text { Irrigation } \\
\text { treatment }\end{array}$ & Nitrogen treatment & First & $\begin{array}{c}\text { Principal component } \\
\text { Second }\end{array}$ & Third & $\begin{array}{c}\text { Comprehensive } \\
\text { evaluation }\end{array}$ & Ranking \\
\hline \multirow{4}{*}{$\mathrm{W}_{1.05}$} & $\mathrm{~N}_{1.00}$ & -2.256 & 2.670 & -0.330 & -0.28 & 11 \\
& $\mathrm{~N}_{0.75}$ & -1.254 & 1.693 & 0.249 & 0.00 & 8 \\
& $\mathrm{~N}_{0.50}$ & -0.744 & 1.590 & 0.886 & 0.35 & 5 \\
\hline & $\mathrm{N}_{0.25}$ & -1.145 & 0.205 & -0.959 & -0.68 & 15 \\
$\mathrm{~W}_{0.90}$ & $\mathrm{~N}_{1.00}$ & -1.380 & 1.471 & -0.435 & -0.28 & 10 \\
& $\mathrm{~N}_{0.75}$ & -0.484 & 1.060 & 0.513 & 0.22 & 6 \\
& $\mathrm{~N}_{0.50}$ & 0.840 & 0.905 & 2.462 & 1.22 & 2 \\
& $\mathrm{~N}_{0.25}$ & -0.784 & -0.255 & -0.960 & -0.66 & 9 \\
$\mathrm{~W}_{0.75}$ & $\mathrm{~N}_{1.0}$ & -0.333 & 0.669 & -0.265 & 0.00 & 3 \\
& $\mathrm{~N}_{0.75}$ & 1.102 & -0.075 & 1.369 & 0.79 & 1 \\
& $\mathrm{~N}_{0.50}$ & 1.640 & 0.543 & 3.199 & 1.64 & 13 \\
\hline & $\mathrm{N}_{0.25}$ & 0.277 & -1.621 & -1.027 & -0.61 & 7 \\
$\mathrm{~W}_{0.60}$ & $\mathrm{~N}_{1.00}$ & 0.187 & -0.811 & -1.271 & -0.45 & 4 \\
& $\mathrm{~N}_{0.75}$ & 1.447 & -1.630 & -0.268 & 0.10 & 12 \\
\hline
\end{tabular}

C. annuum positively correlates with nitrogen level supplies [34]. However, these authors tested much lower, suboptimal nitrogen levels (between $0 \sim 75 \mathrm{~kg} \cdot \mathrm{hm}^{-2}$ ), so that any increase will be positive. This has also been observed by others [35]. Here, we compared nitrogen levels from 150 to $225 \mathrm{~kg} \cdot \mathrm{hm}^{-2}$ which covered the complete range from suboptimal to overfertilization. Candido et al. compared four nitrogen levels ( 0 , 100,200 , and $300 \mathrm{~kg} \cdot \mathrm{hm}^{-2}$ ) under $100 \% \mathrm{ET}_{c}$ water level and showed that the aboveground biomass, individual fruit mass, and fruit thickness increased first and then decreased with an increase of nitrogen level [36]. Their study resulted in optimal fruit indexes at a nitrogen level of $200 \mathrm{~kg} \cdot \mathrm{hm}^{-2}$, which is comparable to our findings, though our results indicate an optimal window instead of absolute values, which is of more practical use for farmers. The optimal water supply has also been studied by Gupta and coworkers, who compared $100 \% \mathrm{ET}, 80 \% \mathrm{ET}$, and $60 \% \mathrm{ET}$ in combination with three NPK levels (150:90:60 kg.hm ${ }^{-2}$, at 100, 80, and 60\%). Their results indicated that, under the same water level, the DM of C. annuum increased with nitrogen level, while $80 \%$ ET water level was favorable for fruit growth, giving an optimal combination of $80 \%$ ET and $80 \%$ NPK to maximize DM [33]. Our results corroborate these findings and also show the beneficial effects of a limited water stress. For sunflowers it was shown that severe drought can greatly reduce the DM, but under proper water levels, the crop growth rate can be increased by higher nitrogen levels [37]. However, for that crop the consumption of nitrogen did not change the relative growth rate and net absorption rate, consistent with findings we report here. Likewise, in previous studies concerning watermelon and muskmelon $[21,38]$, it was concluded that moderate water and nutrient conditions are best for vegetable growth.
Our results show that nitrogen fertilizer corresponding with $150-225 \mathrm{~kg} \cdot \mathrm{hm}^{-2} \mathrm{~N}$ in combination with irrigation conditions representing from $75 \%$ to $90 \% \mathrm{ET}_{0}$ results in high individual plant and economic yields, while outside this range too much or too little water and nitrogen result in negative effects. This conclusion is consistent with previous works $[10,14,39]$. When zooming in on the partial factor productivity from applied nitrogen (PFPN), under the same water level, this factor decreases with an increase of nitrogen. Conversely, under the same nitrogen level, the PFPN increases first and then decreases with water supply, consistent with conclusions obtained by others [39]. Economic yields of C. annuum under test conditions have been reported as $27.29 \sim 65.69 \mathrm{t} \cdot \mathrm{hm}^{-2}$ with a WUE of $14.72 \sim 32.90 \mathrm{~kg} \cdot \mathrm{m}^{-3}$ and as $29.72 \sim 46.54 \mathrm{t} \cdot \mathrm{hm}^{-2}$ with a WUE of $7.76 \sim 10.71 \mathrm{~kg} \cdot \mathrm{m}^{-3}$ [40]. Yields as $21.01 \sim 35.30 \mathrm{t} \cdot \mathrm{hm}^{-2}$ with a WUE of $4.7 \sim 7.9 \mathrm{~kg} \cdot \mathrm{m}^{-3}$ [23] or economic yields of $14.6 \sim 50.3 \mathrm{t} \cdot \mathrm{hm}^{-2}$ [37], WUE of $7.8 \sim 12.3 \mathrm{~kg} \cdot \mathrm{m}^{-3}$ [41], or $4.1 \sim 6.7 \mathrm{~kg} \cdot \mathrm{m}^{-3}$ [42] have also been reported. Compared to these published results, the economic yield under optimal conditions as determined here $\left(31.63 \sim 34.85 \mathrm{t} \cdot \mathrm{hm}^{-2}\right.$ with a WUE of $15.03 \sim 16.50 \mathrm{~kg} \cdot \mathrm{m}^{-3}$ ) had greatly improved. In part, this may be due to the type of $C$. annuum used, while the fact that experiments were conducted in a protected environment may also have helped. However, the positive effect of the online intelligent irrigation fertilizer applicator cannot be ignored, which, when set correctly, increases the utilization efficiency of both water and fertilizer.

After comprehensive consideration of economic yield, water-nitrogen use efficiency, and fruit quality, it was concluded that $\mathrm{W}_{0.90} \mathrm{~N}_{0.75}$ resulted in the highest economic yield, with slightly reduced water-nitrogen use efficiency and quality. Although $\mathrm{W}_{0.75} \mathrm{~N}_{075}$ resulted in the highest WUE with economic yield comparable to $\mathrm{W}_{0.90} \mathrm{~N}_{0.75}$, its nitrogen use 
efficiency was poor. $\mathrm{W}_{0.75} \mathrm{~N}_{0.50}$ resulted in lower economic yields. Compared to locally applied treatment $\mathrm{W}_{1.05} \mathrm{~N}_{1.00}$ our optimal condition could increase yields by $15.22 \%$ with WUE improved by $52.06 \%$. At the same time, fruits produced under $\mathrm{W}_{0.75} \mathrm{~N}_{0.50}$ had excellent scores for contents of capsaicin, $\mathrm{V}_{\mathrm{c}}$, and soluble solids, while the nitrates mass fraction was lower than the standard limit. In addition, the soluble sugar mass fraction was high, ensuing tasteful fruit.

In this study, principal component analysis was used to analyze the main factors affecting fruit quality. The results (Table 4) show that conditions $\mathrm{W}_{0.90}, \mathrm{~W}_{0.75}, \mathrm{~N}_{0.75}$, and $\mathrm{N}_{0.50}$, resulted in fruit of good quality. $\mathrm{W}_{0.75} \mathrm{~N}_{0.50}, \mathrm{~W}_{0.90} \mathrm{~N}_{0.50}$, and $\mathrm{W}_{0.75} \mathrm{~N}_{0.75}$ produce the top 3 rankings, while $\mathrm{W}_{0.60} \mathrm{~N}_{0.25}$ ranks last. $\mathrm{W}_{0.75} \mathrm{~N}_{0.75}$ has the best water-nitrogen coupling effect, and $\mathrm{W}_{0.60} \mathrm{~N}_{0.25}$ confines the absorption of nutrients into the fruits, resulting in poor fruit quality. Other studies have also shown that proper water-nitrogen supply cannot only promote plant growth and fruit development [19] but also enhances fruit quality with no apparent reduction in yield [21,43,44]. These results are consistent with our work. Thus, it is plausible to improve the mass fraction of nutrients in C. annuum by adjusting water-nitrogen application. Moreover, an intelligent irrigation fertilizer can precisely apply and control fertilization based on the amount of irrigation water, providing accurate technical parameters for water and fertilizer integrated large-scale cultivation of C. annuum.

\section{Conclusions}

Experimental culture of $C$. annuum with precisely dosed water and nitrogen supplies in a greenhouse located in the northwest of China identified an optimal window between $75 \%$ and $90 \% \mathrm{ET}_{0}$ and between $50 \%$ and $75 \%$ of conventionally used nitrogen fertilizer, resulting in an increase of economic yields of over $20 \%$, with a simultaneous increase in DM, PPFN, and fruit quality, and an improved WUE. These insights are extremely valuable for farming practices.

\section{Conflicts of Interest}

The authors declare that they have no conflicts of interest.

\section{Authors' Contributions}

Youzhen Xiang and Haiyang Zou contributed equally to the manuscript.

\section{Acknowledgments}

This study was jointly supported by the National Key Research and Development Program of China (2017YFC0403303), the National High-Tech R\&D Program, China 863 Program, (2011AA100504), the National Key Research and Development Program of China (2016YFC0400202), and the National Natural Science Foundation of China (51579211).

\section{References}

[1] D. Jackson-Smith, Toward Sustainable Agricultural Systems in the 21st Century, 2010.

[2] R. B. Thompson, C. Martínez-Gaitan, M. Gallardo, C. Giménez, and M. D. Fernández, "Identification of irrigation and $\mathrm{N}$ management practices that contribute to nitrate leaching loss from an intensive vegetable production system by use of a comprehensive survey," Agricultural Water Management, vol. 89, no. 3, pp. 261-274, 2007.

[3] J. Pretty, "Agricultural sustainability: Concepts, principles and evidence," Philosophical Transactions of the Royal Society B: Biological Sciences, vol. 363, no. 1491, pp. 447-465, 2008.

[4] M. Romic and D. Romic, "Heavy metals distribution in agricultural topsoils in urban area," Environmental Geology, vol. 43, no. 7, pp. 795-805, 2003.

[5] K. Roma and A. Kaushal, "Drip Fertigation in Sweet Pepper: A Review," Journalof Engineering Research and Applications, vol. 8, pp. 144-149, 2014.

[6] J. H. Cai, C. G. Shao, and Z. H. Zhang, "Water demand and irrigation scheduling of drip irrigation for cotton under plastic mulch," Journal of Hydraulic Engineering, vol. 33, no. 11, pp. 119123, 2002.

[7] A. Silber, M. Bruner, E. Kenig et al., "High fertigation frequency and phosphorus level: Effects on summer-grown bell pepper growth and blossom-end rot incidence," Plant and Soil, vol. 270, no. 1, pp. 135-146, 2005.

[8] M. Cui, F. Wang, and H. Xu, "Response of Physiologicalbiochemical Characters of Sweet Pepper Seedlings," Chinese Agricultural Science Bulletin, vol. 21, no. 5, p. 225, 2005.

[9] L. M. Reyes, D. C. Sanders, and W. G. Buhler, "Evaluation of slow-release fertilizers on bell pepper," HortTechnology, vol. 18, no. 3, pp. 393-396, 2008.

[10] M. K. Xian, B. Y. Wang, and Y. W. Yuan, "Research progress of nitrogen in vegetable crops (bell pepper)," Modern agricultural science and technology, vol. 7, pp. 6-9, 2006.

[11] A. S. Lodhi, A. Kaushal, and K. G. Singh, "Impact of irrigation regimes on growth, yield and water use efficiency of sweet pepper," Indian Journal of Science and Technology, vol. 7, no. 6, pp. 790-794, 2014.

[12] S. M. Sezen, A. Yazar, and S. Eker, "Effect of drip irrigation regimes on yield and quality of field grown bell pepper," Agricultural Water Management, vol. 81, no. 1-2, pp. 115-131, 2006.

[13] F. M. del Amor, "Yield and fruit quality response of sweet pepper to organic and mineral fertilization," Renewable Agriculture and Food Systems, vol. 22, no. 3, pp. 233-238, 2007.

[14] T. R. Abu-Zahra, "Vegetative, flowering and yield of sweet pepper as influencedby agricultural practices," Middle East Journal of Scientific Research, vol. 11, no. 9, pp. 1220-1225, 2012.

[15] R. Kumari, A. Kaushal, and K. G. Singh, "Water use efficiency of drip fertigated sweet pepper under the influence of different kinds and levels of fertilizers," Indian Journal of Science and Technology, vol. 7, no. 10, pp. 1538-1543, 2014.

[16] T. B. S. Rajput and N. Patel, "Water and nitrate movement in drip-irrigated onion under fertigation and irrigation treatments," Agricultural Water Management, vol. 79, no. 3, pp. 293311, 2006.

[17] T. M. Darwish, T. W. Atallah, S. Hajhasan, and A. Haidar, "Nitrogen and water use efficiency of fertigated processing potato," Agricultural Water Management, vol. 85, no. 1-2, pp. 95104, 2006. 
[18] M. Šturm, N. Kacjan-Maršić, V. Zupanc, B. Bračič-Železnik, S. Lojen, and M. Pintar, "Effect of different fertilisation and irrigation practices on yield, nitrogen uptake and fertiliser use efficiency of white cabbage (Brassica oleracea var. capitata L.)," Scientia Horticulturae, vol. 125, no. 2, pp. 103-109, 2010.

[19] Y. Xing, C. F. Zhang, and F. L. Wu, "Determination of appropriate drip fertigated system based on tomato yield, quality, water and fertilizer use efficiency," Transactions of the Chinese Society of Agricultural Engineering (Transactions of the CSAE), vol. 31, Supp. 1, pp. 110-121, 2015.

[20] D.-P. Fang, F.-C. Zhang, J. Li, H.-D. Wang, Y.-Z. Xiang, and Y. Zhang, "Effects of irrigation amount and various fertigation methods on yield and quality of cucumber in greenhouse," Chinese Journal of Applied Ecology, vol. 26, no. 6, pp. 1735-1742, 2015.

[21] X. Yang, X. Zhang, J. Ma et al., "Effects of drip fertigation on growth, yield and quality of watermelon in plastic greenhouse," Nongye Gongcheng Xuebao, vol. 30, no. 7, pp. 109-118, 2014.

[22] H.-M. Zhou, F.-C. Zhang, K. Roger et al., "Peach yield and fruit quality is maintained under mild deficit irrigation in semi-arid China," Journal of Integrative Agriculture, vol. 16, no. 5, pp. 11731183, 2017.

[23] S. M. Sezen, A. Yazar, Y. Daşgan et al., "Evaluation of crop water stress index (CWSI) for red pepper with drip and furrow irrigation under varying irrigation regimes," Agricultural Water Management, vol. 143, pp. 59-70, 2014.

[24] H. S. Li, Principles and techniques of plant physiology and biochemistry experiment, 2000.

[25] X. Chen, Y. F. Ma, and G. Z. Fang, "Preliminary study on the influence of soil moisture on yield and quality of processed tomato," Water Saving Irrigation, vol. 4, pp. 1-4, 2006.

[26] H. Feng, X. Liu, Y. Zuo, and K. Yu, "Effect of gravel mulching degree on farmland moisture and water consumption features of crops," Nongye Jixie Xuebao/Transactions of the Chinese Society for Agricultural Machinery, vol. 47, no. 5, pp. 155-163, 2016.

[27] R. Allen G, L. Pereira S, D. Raes, and M. Smith, Crop Evapotranspiration: Guidelines or Computing Crop Water Requirements, vol. 56, FAO Irrigation and Drainage, Rome, 1998.

[28] M. X. Chen, J. H. Cai, and X. H. Li, "Calculation of crop evapotranspiration in greenhouse," The Journal of Applied Ecology, vol. 18, no. 2, pp. 317-321, 2007.

[29] L. Wu, F. Zhang, H. Zhou et al., "Effect of drip irrigation and fertilizer application on water use efficiency and cotton yield in North of Xinjiang," Nongye Gongcheng Xuebao, vol. 30, no. 20, pp. 137-146, 2014.

[30] A. Ierna, G. Pandino, S. Lombardo, and G. Mauromicale, “Tuber yield, water and fertilizer productivity in early potato as affected by a combination of irrigation and fertilization," Agricultural Water Management, vol. 101, no. 1, pp. 35-41, 2011.

[31] C. A. Norwood, "Water use and yield of limited-irrigated and dryland corn," Soil Science Society of America Journal, vol. 64, no. 1, pp. 365-370, 2000.

[32] A. J. Gupta, M. F. Ahmad, and F. N. Bhat, "Studies on yield, quality, water and fertilizer use efficiency of capsicum under drip irrigation and fertigation," Indian Journal of Horticulture, vol. 67, no. 2, pp. 213-218, 2010.

[33] T. Gadissa and D. Chemeda, "Effects of drip irrigation levels and planting methods on yield and yield components of green pepper (Capsicum annuum, L.) in Bako, Ethiopia," Agricultural Water Management, vol. 96, no. 11, pp. 1673-1678, 2009.
[34] J. O. Ayodele, O. E. Alabi, and M. Aluko, "Nitrogen Fertilizer Effects on Growth, Yield and Chemical Composition of Hot Pepper (Rodo)," International Journal of Agriculture and Crop Sciences, vol. 8, no. 5, p. 666, 2015.

[35] S. I. M. Khan, S. Roy, and K. K. Pall, "Nitrogen and phosphorus efficiency on the growth and yield attributes of Capsicum," Academic Journal of Plant Sciences, vol. 3, no. 2, pp. 71-78, 2010.

[36] V. Candido, V. Miccolis, and A. R. Rivelli, "Yield traits and water and nitrogen use efficiencies of bell pepper grown in plasticgreenhouse," Italian Journal of Agronomy, vol. 4, no. 3, pp. 91100, 2009.

[37] M. Mojaddam, S. Lack, and A. Shokuhfar, "Effects of water stress and different levels of nitrogen on yield, yield components and WUE of sunflower hybrid iroflor," Advances in Environmental Biology, vol. 5, no. 10, pp. 3410-3417, 2011.

[38] W. Yue, F. Zhang, Z. Li, H. Zou, and Y. Gao, "Effects of water and nitrogen coupling on nitrogen uptake of muskmelon and nitrate accumulation in soil," Transactions of the Chinese Society for Agricultural Machinery, vol. 46, no. 2, pp. 88-119, 2015.

[39] A. W. Xu, "High yield fertilizer technology of Pepper," Hebei agricultural science and technology, vol. 6, no. 010, 2002.

[40] Q. Kong, G. Li, Y. Wang, and H. Huo, "Bell pepper response to surface and subsurface drip irrigation under different fertigation levels," Irrigation Science, vol. 30, no. 3, pp. 233-245, 2012.

[41] L. Dalla Costa and G. Gianquinto, "Water stress and watertable depth influence yield, water use efficiency, and nitrogen recovery in bell pepper: Lysimeter studies," Australian Journal of Agricultural Research, vol. 53, no. 2, pp. 201-210, 2002.

[42] N. Dagdelen, E. Yilmaz, F. Sezgin et al., "Effects of Water Stress at Different Growth Stages on Processing Pepper," Pakistan Journal of Biological Sciences, vol. 7, no. 12, pp. 2167-2172, 2004.

[43] J. Z. Li, J. Li, and C. F. Zhang, "Effects of water and nitrogen supply on yield and quality of greenhouse cucumber under fertigation," Journal of northwest agriculture and forestry university of science and technology (natural science edition), vol. 12, no. 022, 2015.

[44] S. C. Lu, L. J. Wang, and G. Yu, "Effects of nitrogen fertilizer on pepper fruit quality and yield," Journal of Northeast Agricultural University, vol. 36, no. 4, pp. 448-450, 2005. 


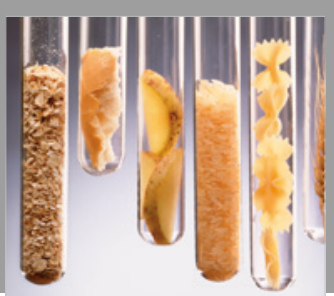

International Journal of Food Science

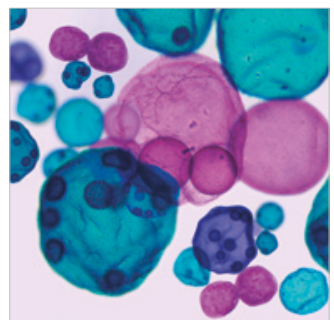

International Journal of Microbiology
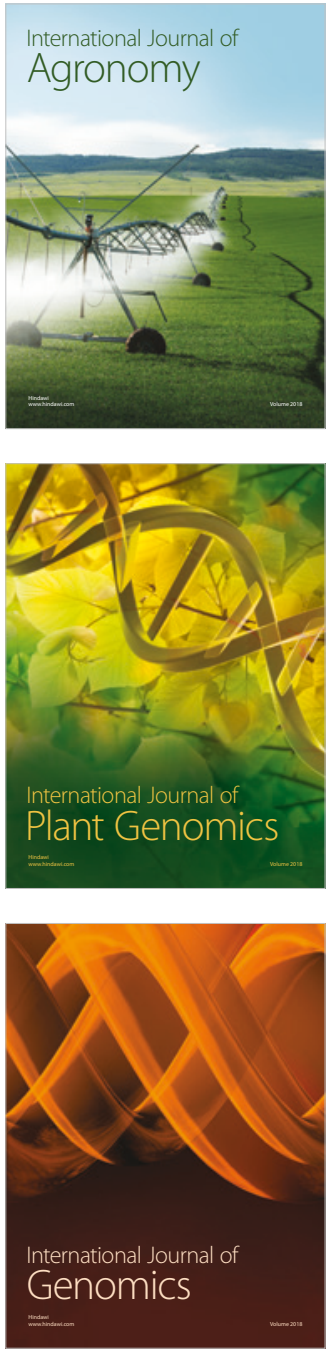

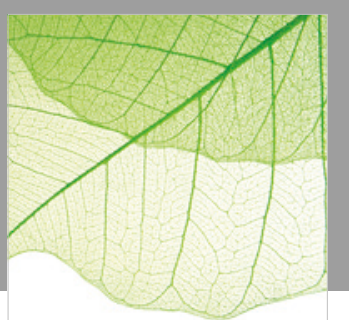

Journal of Botany
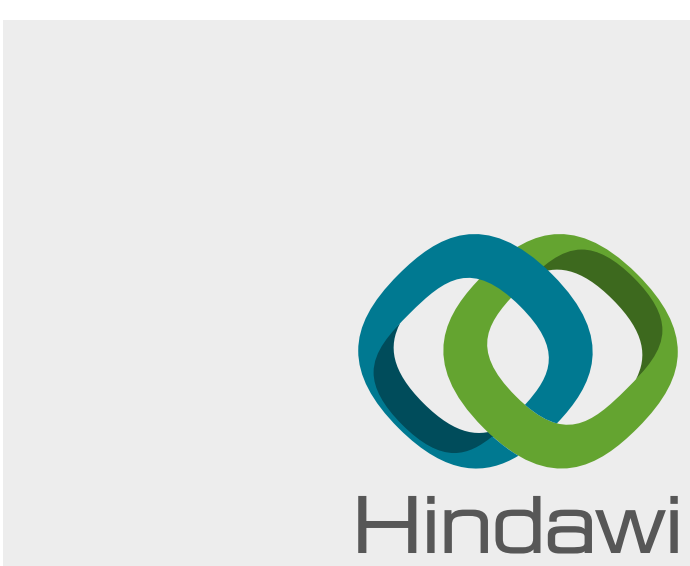

Submit your manuscripts at

www.hindawi.com
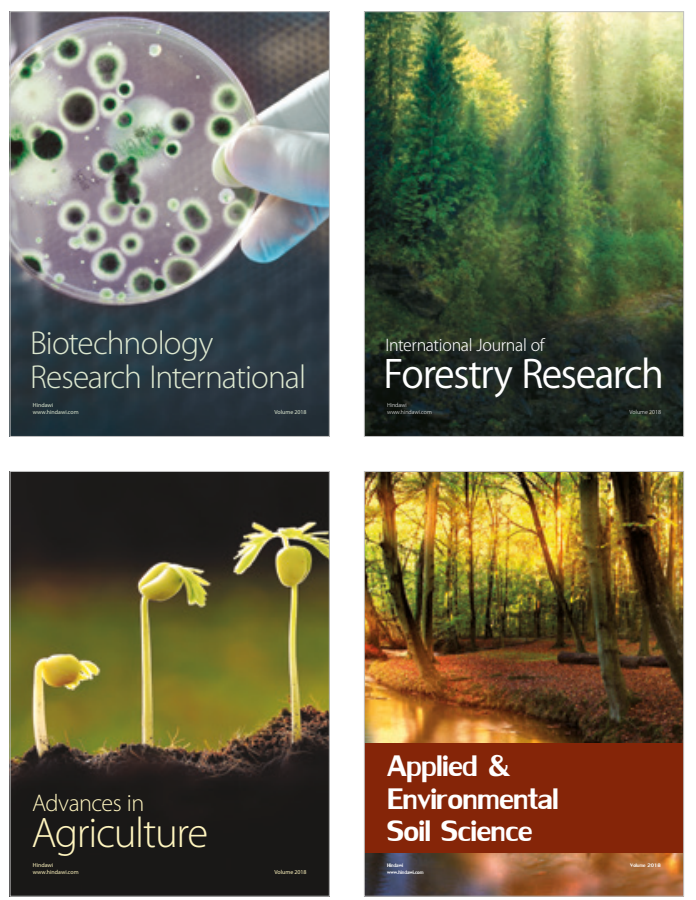

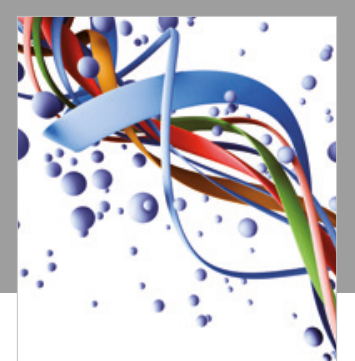

Scientifica

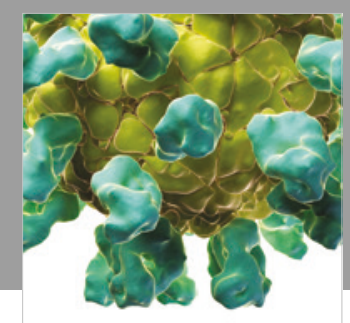

Veterinary Medicine International

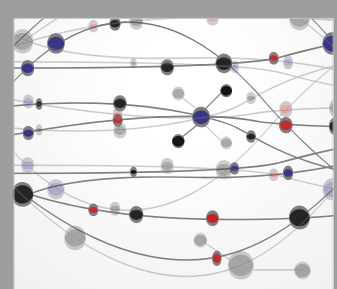

The Scientific World Journal
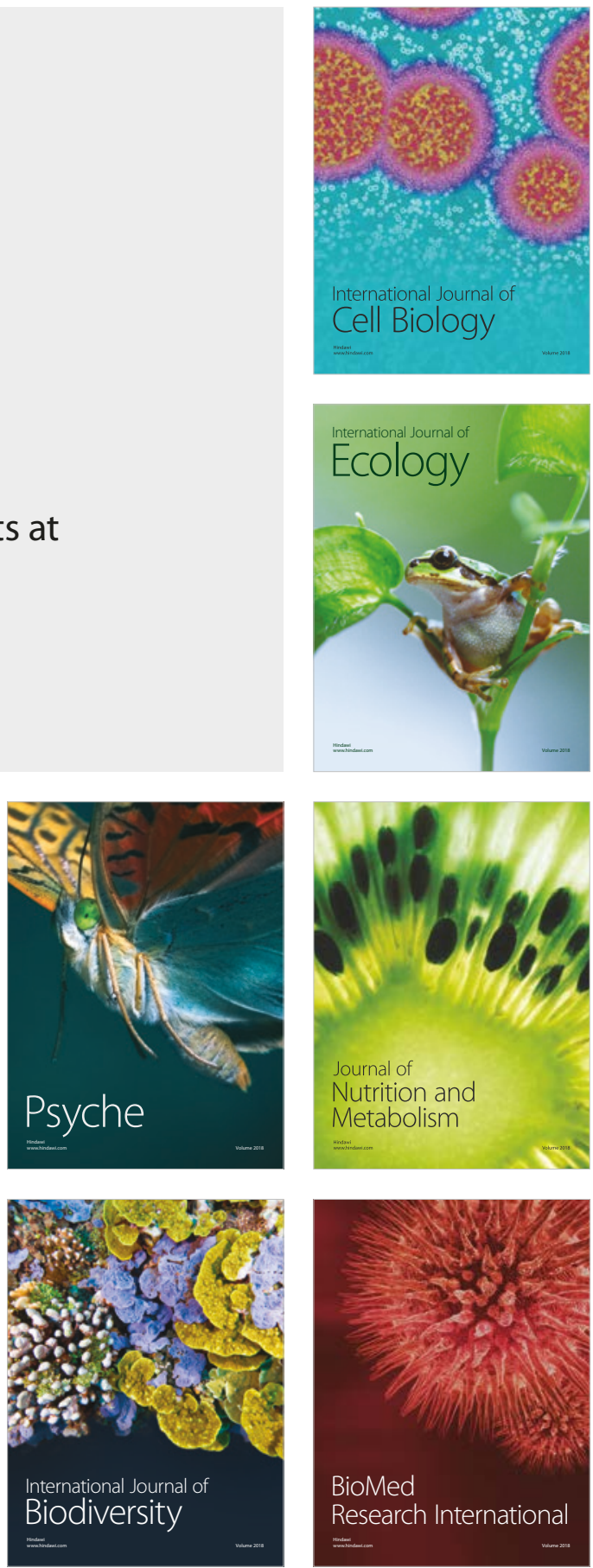